\title{
La parcela doméstica de la casa rural altomedieval (ss. V-XI)
}

Alfonso Vigil-Escalera Guirado

\begin{abstract}
PALABRAS CLAVE: vivienda rural, solar y huerto, arqueología doméstica, arqueología agraria.
\end{abstract}

\section{CÓDIGOS JEL: D13, N33, N53, N83, R2.}

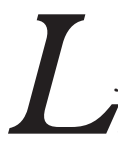

a parcela doméstica es la Cenicienta de la casa rural altomedieval. Aloja la mayor parte de las actividades de mantenimiento y reproducción social, y en ella se procesan y almacenan las cosechas, se supervisa la crianza de los diversos animales, se madura el estiércol y se guardan el equipamiento, las herramientas, el forraje o el combustible. Diversas circunstancias conceptuales y metodológicas han convergido a la hora de relegar la caracterización arqueológica de este espacio sin el que la vivienda rural queda huérfana de contexto. El trabajo abordará su configuración exprimiendo la potencialidad informativa de una serie de casos de estudio del interior peninsular, revisados para la ocasión con arreglo a parámetros homogéneos. Tras plantear los principales problemas que suscita el reconocimiento arqueológico y el análisis de estos recintos, se señalarán los retos que tiene por delante la investigación para generar a partir de estos datos un conocimiento crítico de la sociedad rural altomedieval. 


\title{
The domestic plot of the early medieval farmhouse $\left(5^{\text {th }}-11^{\text {th }} \mathrm{c}\right.$.)
}

\section{KEYWORDS: rural housing, toft and garden, domestic archaeology, agrarian archaeology.}

\author{
JEL CODES: D13, N33, N53, N83, R2.
}

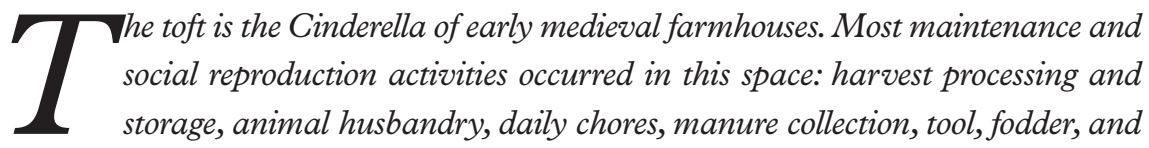
fuel storage, etc. Archaeological characterization of this space was overlooked in convergent conceptual and methodological circumstances and has deprived deprived these dwellings of their context. This paper reviews the informative potential of domestic enclosures by analysing several case studies from inner Iberia, all of which were scrutinized under homogeneous criteria. After addressing the main problems arising from archaeological recognition and analysis of these enclosures, we discuss the research challenges that lie ahead in using these data to generate critical knowledge of early medieval rural society. 


\section{INTRODUCCIÓN}

El objetivo de este trabajo es promover el reconocimiento arqueológico de la parcela doméstica como contenedor y contexto necesario de la vivienda campesina y realizar su caracterización preliminar en el ámbito del poblamiento rural altomedieval de la península Ibérica (siglos V-XI).

La documentación manejada consiste en registros arqueológicos procedentes de distintos tipos de asentamientos rurales, ya sean unifamiliares (de carácter diseminado) o plurifamiliares (agregados), en los que es patente la actividad de varias unidades domésticas. La literatura suele referirse a esos sitios como granjas y aldeas (Vigil-Escalera, 2007). No se abordará aquí su encuadre sociopolítico, económico o antropológico, como tampoco los debates sobre la naturaleza dispersa, agregada o compacta del hábitat (Roberts, 1996: 15-37; Jones, 2010). Queda fuera por tanto la vivienda urbana, cualquiera que haya sido la entidad de esos núcleos, y se evitará -salvo en un caso- el análisis de las levantadas en lugares provistos de elementos de delimitación del área residencial, naturales o artificiales, en alto o en llano, por cuanto la disponibilidad de espacio de las unidades domésticas haya podido quedar constreñida. No se descarta a priori la presencia de un parcelario afín al que trataremos en algunas poblaciones significativas, pero no sería este su rasgo distintivo, como ocurre en el resto.

Una vez reconocida la extensión real del ámbito doméstico es posible identificar, analizar e interpretar los elementos funcionales que efectivamente lo integran, así como su articulación. Esto no supone rebajar la trascendencia del espacio residencial, sino resignificar la vivienda en el marco de sus relaciones con todo aquello que la completa. Enfocada así la investigación, es posible acometer análisis comparativos eficaces a la escala del lugar habitado (reconocer y cuantificar las diferencias existentes entre unidades domésticas) y entre asentamientos. Constituye una base firme para abordar otras cuestiones, como por ejemplo la de la desigualdad, y puede propiciar el reconocimiento de diferencias territoriales. Este enfoque consiente además gestionar el análisis diacrónico de cada unidad y leer el desarrollo orgánico de los conjuntos, su complejización o simplificación a lo largo del tiempo.

Los casos proceden de distintas regiones peninsulares, sobre todo de su cuadrante suroeste, y muestran considerable coherencia a pesar de la variabilidad de las formas de asentamiento, de su contexto histórico y sociopolítico y de los ecosistemas en que se integran (Fig. 1). 


\section{FIGURA 1}

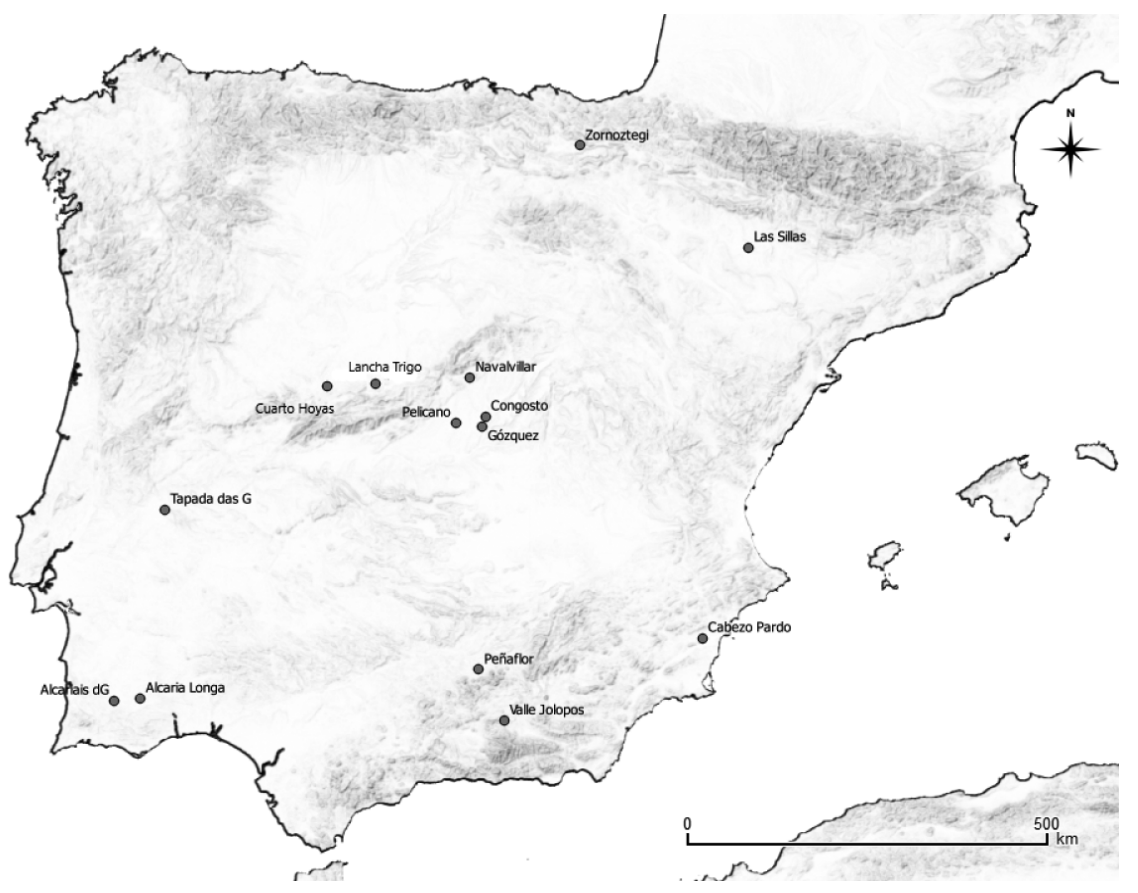

Localización de los lugares citados en el texto

\section{CONSIDERACIONES HISTORIOGRÁFICAS}

Las investigaciones relacionadas con la arqueología agraria y la del campesinado altomedieval han progresado de forma considerable en España (Quirós, 2011, 2018; Kirchner, 2010, 2020; Eiroa, 2012; Quirós et al., 2013; Martín \& Bonet, 2015). Una muestra de esa madurez queda de manifiesto en la apertura de la investigación a las aldeas actualmente habitadas (Fernández Fernández, 2017; Fernández Fernández \& Fernández Mier, 2019), con lo que se desborda el límite de la investigación tradicionalmente establecido en los despoblados.

Otro tanto ha sucedido con la arqueología histórica del espacio doméstico (Gutiérrez Lloret, 2012, 2013, 2015; Tejerizo, 2012; Gutiérrez Lloret \& Grau, 2013; Bermejo, 2014; Díez Jorge \& Navarro, 2015), lográndose avances sustanciales en su puesta al día. La promoción de estos asuntos se integra en la consolidada corriente internacional de la household archaeology ${ }^{1}$. Un lenguaje común y el manejo de unos ejes conceptuales y me-

1. Véanse al respecto Yanagisako (1979), Wilk y Rathje (1982), Netting et al. (1984), Blanton (1994), Laurence y Wallace-Hadrill (1997), Allison (1999), Barile y Brandon (2004), 
todológicos coherentes (Hirth, 1992) hacen posibles lecturas transculturales y de larga duración (Hammel \& Laslett, 1974; Gerritsen, 2008).

Con todo, el conocimiento de la vivienda sigue adoleciendo de cierto retraso, sobre todo en lo que atañe al análisis integral del espacio doméstico. Ciertos factores han podido incidir en que, al hablar de casas medievales, las investigaciones se hayan ceñido al espacio delimitado por sus muros. El hecho de que la casa rural se inserte naturalmente en una parcela ha sido con frecuencia obviado. Por regla general, salvo en los casos en que el patrón residencial se defina por la dispersión, es la agregación laxa o la yuxtaposición de parcelas domésticas lo que conforma la trama de la mayor parte de los asentamientos. El ejemplo y la tradición de estudio de la vivienda urbana de la antigüedad clásica, por un lado, y la limitada extensión de las exploraciones arqueológicas convencionales, por otro, son cuestiones a tener en cuenta. Es posible también que el modelo de pueblo compacto del final de la Edad Media -vigente hasta nuestros días en la mayor parte del territorio- haya condicionado nuestros mapas mentales, inhibiendo las pesquisas sobre el formato de espacio doméstico que sin duda prevaleció en el ámbito rural desde el final del Imperio romano hasta bastante después del año mil en amplias zonas.

Hace unos años, la propuesta de un protocolo de investigación sobre los asentamientos rurales y la arqueología agraria (Ballesteros et al., 2010: 185) formulaba la necesidad de reconstruir conceptualmente los estudios sin segregar los espacios productivos. A menudo se asume que los espacios de trabajo campesinos han de encontrarse casi por definición disociados de los residenciales (Kirchner, 2020: 466-467). Se identifican preferentemente con campos de cultivo, pastos, montes, etc. Sin embargo, es en la propia casa, entendida en un sentido amplio como unidad de explotación, donde más se trabaja. En ella se desarrollan muchas de las tareas de procesado y transformación de la producción, se almacenan las reservas de alimentos, combustible o forraje, se custodian las herramientas y equipamiento, se prepara diariamente el rancho, se alimenta y cuida a las aves de corral, y se guarece durante ciertos periodos al ganado. A todo ello deben sumarse las variadas actividades artesanales desempeñadas por los miembros del grupo en régimen de pluriactividad (textiles, de cestería, conservas alimentarias, etc.). La consideración de muchas de ellas como actividades de mantenimiento (González Marcén, Montón \& Picazo, 2008; Díaz Andreu \& Montón, 2012: 443-445) no las extraña conceptualmente de las de producción, ni las coloca en una situación de subalternidad.

PARKer y Foster (2012). Sobre la domesticidad medieval, véanse, por ejemplo, HerLiHy (1985), Pesez (1990, 1998), García Camino (1998), Bazzana y Hubert (2000), y Kowaleski y GoldBERG (2008). 
La casa rural puede integrar a veces una pequeña parcela agraria que cabría denominar huerto. Los documentos escritos de los siglos IX y x del norte peninsular contienen cientos de referencias a estos espacios (Davies, 2019: 334). Solo en contadas ocasiones esos huertos quedan englobados en la trama del asentamiento y pueden caracterizarse arqueológicamente. Es previsible que muchas otras veces se localicen a escasa distancia de las viviendas, fuera del rango de las exploraciones.

Gutiérrez Lloret $(2012,2013,2015)$ ha propuesto distinguir tres niveles de análisis arqueológico del espacio doméstico: el morfológico, el sintáctico (referido a las relaciones entre elementos) y el semiótico (la arquitectura como forma de expresión y reproducción de la sociedad que la genera). Como corresponde a una aproximación preliminar, el énfasis del presente trabajo se pondrá en el primero de esos itinerarios. Su modelo de clasificación de la vivienda abarca cuatro categorías: módulo unicelular, módulos asociados, módulos agregados delimitando un "protopatio» y unidad modular compleja estructurada en torno a un patio o "casa de patio» (Gutiérrez Lloret, 2015: 22, Fig. 2). La propuesta mejora y amortiza otras anteriores (Bazzana, 1992, 2002), aunque, ceñida al análisis de la residencia desde una perspectiva urbana, no contempla más que en sus estadios finales ese ámbito englobante que es la parcela doméstica, insoslayable para una aproximación integral a la casa rural.

Una parte de las investigaciones sobre la casa medieval, su desarrollo orgánico a lo largo del tiempo y la articulación del espacio doméstico en general (en al-Ándalus principalmente) ha girado en torno a la génesis y desarrollo del patio y a la creciente especialización funcional del contenedor residencial (Navarro, 1990; Bazzana, 1990, 1992; Gutiérrez Lloret, 2015; Boone, 2019: 23-24). Suele partirse de un concepto evolucionista lineal que conduciría de lo sencillo a lo complejo ${ }^{2}$. Se sobreentiende que la vivienda pudo haber sido en origen una construcción aislada, sin un entorno doméstico establecido (Fig. 2).

Esa premisa determina que haya tratado de localizarse el origen de los primeros elementos de delimitación de las granjas. La aparición de límites parcelarios en la Inglaterra altomedieval, por ejemplo, quedaría arqueológicamente atestiguada a partir de finales del siglo VI y el siglo VII (Brookes \& Reynolds, 2019: 289; Reynolds, 2003), cuando también alude a ese fenómeno la legislación de la época ${ }^{3}$. Se acepta en cambio sin repa-

2. «[...] estamos ante procesos formativos largos que pueden partir incluso de un módulo unicelular o de módulos asociados que se van agregando a lo largo del tiempo, cuyo principal proceso de complejización y el último en la secuencia constructiva, es generalmente la demarcación de los confines del 'protopatio'" (GUTIÉRREZ LLORET, 2015: 24).

3. El código legal de Kent, hacia el año 600, menciona el cercado de una persona, probablemente una granja (BROOKES \& REYNOLDS, 2019: 289). La referencia textual y el testimonio arqueológico se 
ros la existencia previa de recintos en asentamientos eclesiásticos o nobiliarios (por ejemplo, Swan, 1994) y de hecho, se sugiere una correspondencia directa entre la formalización del espacio doméstico, el establecimiento de unos límites parcelarios precisos y la prominente categoría del grupo social responsable.

\section{FIGURA 2}
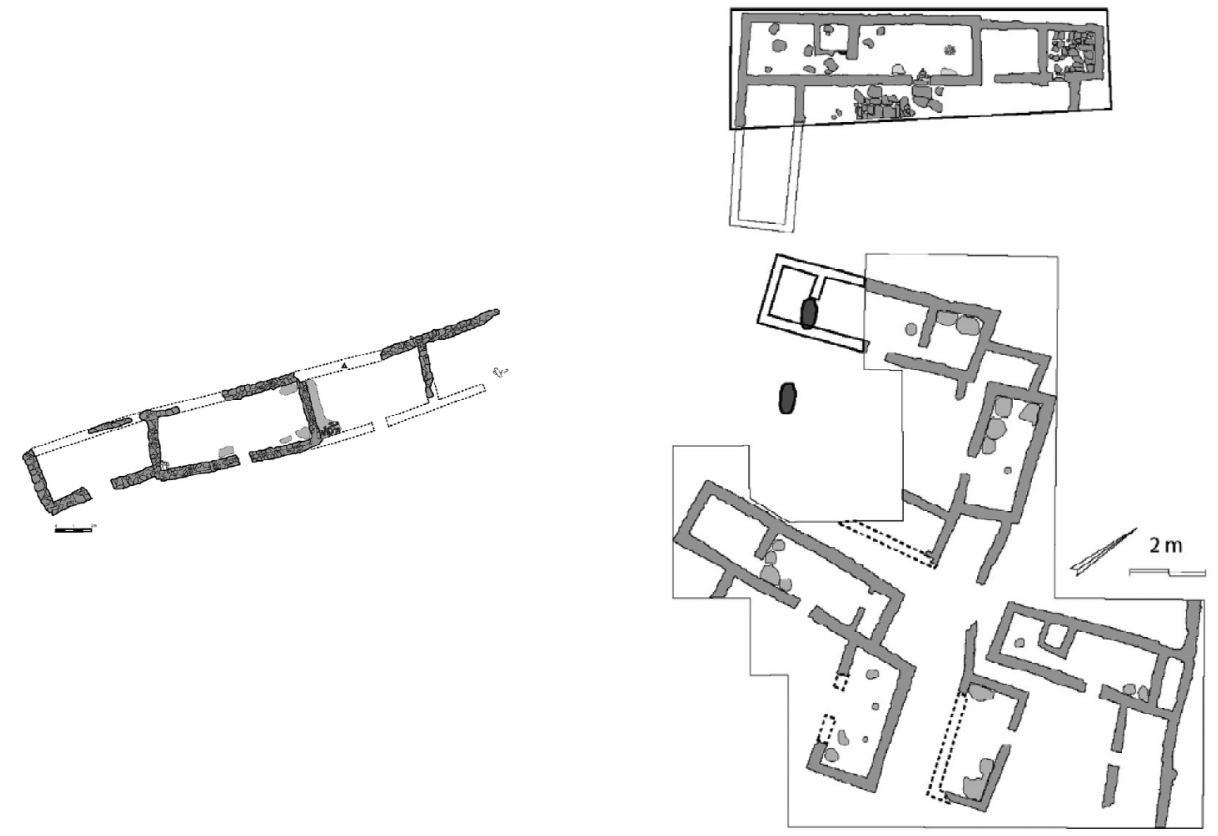

Evolución de la vivienda 'transitoria' de época emiral (Queimada, a la izquierda) a la de época califal-taifa (Alcaria Longa, a la derecha), según Boone (2019: Figs. 4 y 5).

Resulta difícil de concebir, sin embargo, que, incluso en sus formatos más rudimentarios o iniciales, la casa campesina pudiese ser una edificación aislada (Figs. A1-A2) ${ }^{4}$. Es lógico que la delimitación del solar doméstico haya ido institucionalizándose con el tiempo y parece razonable asumir que las estructuras de cierre hayan tendido no solo a construirse

yuxtaponen para reforzar la supuesta inexistencia o escasa relevancia de tales límites con anterioridad. No obstante, la delimitación del parcelario doméstico está bien documentada a mediados del primer milenio antes de la Era en el norte de Europa (Moore, 2007: 264, Figs. 3, 9), o en la Edad del Bronce chipriota (FRANKEL \& WEBB, 2006). La Irlanda altomedieval se aborda integralmente en O’Sullivan y Nicholl (2011).

4. Las figuras no incluidas en la versión impresa pueden consultarse en el anexo en línea. DOI https://doi.org/10.26882/histagrar.086x04v 
con mayor solidez, sino a fijarse y perdurar. Reconocer la progresiva complejización del espacio doméstico, un espacio en el que se articulan elementos con una creciente especialización tipológica y funcional, no debería implicar la admisión de un punto de partida en el que la casa carece de un entorno formalizado para los usos que le son propios. Como decía un sociólogo citado por Bazzana, «une maison sans cour n'en est pas une» (Bazzana, 2002: 230).

Parece necesario abordar el análisis arqueológico del espacio doméstico de una forma más holística de lo que se ha hecho hasta ahora. Esto implica prestar atención a lo que, formando parte de la casa campesina y perteneciendo al dominio privado de la unidad doméstica (en adelante UD), se encuentra fuera de la vivienda, aunque inmediata a ella. Un buen punto de partida sería la caracterización de ese ámbito a partir de sus dimensiones básicas: forma, tamaño y cronología.

\section{DEFINICIONES Y CONTRAPARTIDAS MATERIALES}

Entendemos por casa campesina a efectos del presente trabajo el conjunto de edificios, estructuras auxiliares y espacios para actividades de mantenimiento que conforman el equipamiento inmueble necesario para la supervivencia cotidiana del grupo familiar o UD y generalmente para su reproducción intergeneracional, con independencia de cuáles sean las relaciones entre quienes la integran y del plazo temporal en que se sustancie esa vinculación.

Una mínima porción de las edificaciones rurales tuvo un carácter excepcional, tanto en época visigoda como en la andalusí. Pudieron ser el centro de explotaciones agrarias de cierta entidad, laicas o religiosas, o servir como residencias aristocráticas o de cargos de la Administración. Al centrarnos en la casa campesina excluiremos del análisis esos casos.

Guardando distancia respecto de ciertos apriorismos historiográficos, la lectura del registro arqueológico sugiere que, en las coordenadas espaciotemporales del presente trabajo, la UD está compuesta de forma habitual por una familia nuclear, no siendo extraño que un número indeterminado de consanguíneos o servidores domésticos pueda a veces englobarse en ella. Las vicisitudes que puede sufrir la composición de la UD a lo largo del tiempo (Dyer, 2013: 24) llevan aparejadas con frecuencia transformaciones en la materialidad de la casa. Estas tienen ante todo un componente biológico o reproductivo: la supervivencia de unos abuelos longevos, la corresidencia de hermanos solteros o viudos del padre o la madre, el número y la edad de los hijos, su comportamiento residencial antes y después de contraer matrimonio, etc. El tamaño de la UD está sujeto a unas limi- 
taciones primarias tales como el terrazgo a su disposición (extensión y calidad), la mano de obra movilizable y el capital acumulado en forma de herramientas, simiente o ganado (en tanto reserva de alimento y fuente de productos secundarios y estiércol), pero también la porción que puede disfrutar de otros recursos (pastos, monte, pesca, caza...) en su calidad de partícipes de una comunidad, sea o no de corresidentes. La composición de la UD es también una variable dependiente del éxito o fracaso de la explotación a lo largo de ciclos anuales y plurianuales, que puede provocar desequilibrios entre la mano de obra disponible y la carga indispensable de trabajo. La presencia de servidores domésticos y su número, o la contratación de jornaleros para determinadas tareas estacionales depende en buena medida de la riqueza acumulada por la familia, del estado de sus tierras y ganados y de la pericia con la que se consiga sacar adelante la explotación en el caso de no mediar años malos por la enfermedad, la meteorología, las plagas u otros factores impredecibles (incendios, robos, etc.).

$\mathrm{El}$ análisis arqueológico del espacio doméstico debe afrontar, por tanto, un universo de situaciones potenciales casi ilimitado. La foto fija obtenida mediante la intervención arqueológica, por mucha profundidad cronológica que puedan brindar los restos materiales preservados, es siempre un pálido reflejo de la cambiante configuración real de la UD a lo largo de su existencia y su plasmación física en la casa.

Los exhaustivos análisis de Dyer sobre las casas campesinas inglesas de la Baja Edad Media (1994: 139) indican el pequeño tamaño que solía tener el solar edificado que era el centro de la explotación (normalmente menos de mil metros cuadrados), ya sea dispuesto al lado del de sus vecinos a lo largo de un camino o prado o al cabo de una vía de acceso en las áreas de asentamiento disperso. Las parcelas solían tener forma rectangular y se cerraban por medio de un terraplén, seto, valla o tapia, a veces con una trinchera exterior. Estas estructuras lineales, cada vez más habituales en la literatura arqueológica europea cuando median intervenciones en extensión, apenas se han documentado en nuestro entorno. Puede deberse a la imprevisión o al desconocimiento (no se documenta aquello cuya existencia se ignora, como ocurría años atrás con las cabañas de fondo rehundido), aunque también influyen la precariedad de los protocolos de registro y la insuficiente atención prestada a las estructuras «menores» en la periferia del núcleo edificado.

Los arqueólogos ingleses llaman a la parcela doméstica toft, que es el término usado en la documentación de la época en algunas regiones ${ }^{5}$. En los diccionarios también apa-

5. También aparece como messuage, reservándose toft para las parcelas domésticas vacías tras la demolición de las construcciones. 
rece el término croft, definido como «the enclosed yard immediately surrounding the house» (Alcock, 2003: 449). Sin embargo, el glosario del Landscape Research Centre especifica que «toft refers to the land on which the house was built, the croft is the adjoining plot of land used for pasture or arable. Generally seen as narrow parallel strips of land ${ }^{6}$. Tal vez los equivalentes más apropiados en castellano para este binomio sean solar y huerto.

Los edificios que componen la granja se distribuyen habitualmente dentro de un solar cuya parte situada delante de la vivienda suele denominarse patio. Los elementos que con más frecuencia se repiten en las fuentes manejadas por Dyer son la casa, el establo y el granero, si bien las propiedades más complejas pueden incluir cocina separada, cuadra bueyera, vivienda auxiliar, gallinero, apriscos, pocilga, lechería, bodega, etc. La riqueza y el estatus de la UD se evalúan mejor a partir del número y tamaño de las instalaciones auxiliares que por la fábrica, tamaño y contenido de la vivienda principal (Dyer, 1994: 142). El rendimiento previsto de la cosecha determina el de los graneros, y el número de cabezas de ganado, el de los establos y corrales. Los edificios de uso agrícola son la mayor inversión individual que acomete un campesino (Dyer, 1994: 163). Al asegurar la protección de la cosecha y resguardar a los animales y el equipo de trabajo, el gasto hecho en esas instalaciones es su principal contribución a la eficiencia productiva de la granja.

Los avances en la investigación avalan que el espacio doméstico en el ámbito rural altomedieval rebasa con creces el perímetro marcado por los muros de la vivienda. La UD se organiza dentro de una parcela más o menos extensa de usufructo privado en la que es posible distinguir, además de la vivienda principal, toda una serie de estructuras auxiliares y espacios de producción. Estos elementos se distribuyen dentro de un ámbito de límites reconocibles, ya sea por medio de un seto, cerca o tapia, sin un patrón fijo en cuanto a forma o dimensiones. A ellos podría referirse la legislación visigoda cuando, por ejemplo, prescribe multas en el caso de daños en setos o cercados (LVVIII.3.1.2). También establece la equivalencia entre la vivienda y el patio (domum vel curtis) a efectos de lo que se consideraba un espacio privado (LVVIII.1.4).

La ubicación de la vivienda principal en un lugar destacado de la parcela es una circunstancia recurrente. Con frecuencia ocupa la parte más alta de la ladera, lo que asegura una visión ininterrumpida sobre el patio y los elementos que contiene. En Asturias se usa, al menos desde el siglo $\mathrm{x}$, el término quintana para referirse no solo al solar en el que se levanta la casa, sino también a la parcela aneja, también cercada, destinada a huerto

6. http://www.landscaperesearchcentre.org/Project\%203841/glossary.htm (acceso 17/06/2020). Véase también Astill (1988). 
o plantación (García Fernández, 1980: 65-66). De estos huertos, fundamentales en la economía campesina (Veen, 2005), podremos ver luego algún ejemplo.

El registro arqueológico revela muchos de estos elementos, aunque sea parcialmente, en casi todos los asentamientos rurales investigados. Lo que falta en unos aparece en otros, y el examen de todas esas piezas permite dibujar unos rasgos que pueden tener validez universal. Esto no implica que todos los sitios sean sustancialmente iguales. Como veremos, existen rasgos idiosincráticos dentro de la muestra que sugieren una complejidad del universo campesino altomedieval merecedora de atención.

A lo largo del trabajo se expondrá una muestra de datos arqueológicos sobre el solar en que se levanta la casa campesina altomedieval. Se atenderán de forma prioritaria las cuestiones referentes a su morfología y extensión, ubicación de la vivienda principal y cronología, haciendo hincapié en los criterios seguidos para restituir sus confines. Quedarán pendientes de estudio muchos detalles concernientes a la vivienda e instalaciones auxiliares, los problemas de atribución funcional que suelen suscitarse y la articulación espacial de todos esos componentes, así como la diversidad de técnicas constructivas, entre otros temas de interés.

\section{APUNTES METODOLÓGICOS}

El estudio de la parcela doméstica en el ámbito rural altomedieval se ve dificultado por lo esporádica que resulta la conservación y el registro de estructuras de delimitación en la mayor parte de los yacimientos. Experiencias recientes demuestran que es posible documentar esta clase de estructuras sin necesidad de remover el terreno superficial, ya sea a través de la interpretación de la fotografía aérea y de satélite como con prospecciones geofísicas (por ejemplo, Hegyi et al., 2020).

En el repertorio de sitios manejado se han podido documentar mediante excavación arqueológica zanjas de delimitación parcelaria solo en Gózquez, Congosto y El Pelícano. En zonas adehesadas no es extraño que los restos de edificios y tapias puedan reconocerse todavía a través de sus derrumbes o por el característico microrrelieve que generan. Son particularmente expresivas las fotografias de satélite de los sitios anegados por el embalse de Santa Teresa (Pelayos, Salamanca) en las ocasiones en que desciende la lámina de agua. Los cambios en la coloración del terreno permiten reconocer el trazado de muchas estructuras construidas en piedra. 
Con frecuencia, alineaciones de estructuras a lo largo de un límite fantasma testimonian la existencia de recintos de los que no han pervivido restos materiales. Otras veces esos límites se infieren a partir de la disposición de estructuras arqueológicas con determinadas formas y orientaciones. Así, por ejemplo, la documentación de rebajes de plantas subortogonales de escasa profundidad rellenos de sedimentación con alto contenido orgánico suele corresponderse con el interior de edificios cuyos zócalos o rozas perimetrales han desaparecido. Los rebajes se producen a consecuencia del desgaste de los suelos de tierra por el uso y las sucesivas limpiezas de la superficie, de forma que su profundidad guarda cierta relación con el tiempo que la estructura ha estado en activo (Zimmermann, 1999b: 133; Hinsch Mikkelsen et al., 2019: 75). En el caso de viviendas, esas depresiones se suelen ajustar al perímetro interno del zócalo del edificio y presentan ángulos vivos y una base significativamente horizontal. En establos o zonas de cobijo de animales, las plantas resultantes tienen contornos de esquinas redondeadas, y el rebaje presenta con frecuencia una mayor profundidad en el centro o irregularidades. A la postre, la combinación de todos los tipos de testimonios antes mencionados y su distribución ordenada en el espacio es lo que permite establecer con razonable confianza la delimitación de unas parcelas que de otra forma no serían reconocibles.

\section{ANÁLISIS DE CASOS}

\subsection{Tapada das Guaritas (Castelo de Vide, Alto Alentejo, Portugal)}

El sector I de Tapada das Guaritas presenta una parcela doméstica delimitada por una tapia de piedra en seco. De sus tramos preservados se infiere una planta oblonga, dentro de la cual la vivienda ocuparía una posición centrada. Según la restitución propuesta (Fig. A2), el solar tendría unos 39 metros de eje largo (norte-sur) por unos 28 en el corto y una superficie aproximada de $870 \mathrm{~m}^{2}$. Esta extensión se acerca al cuarto de acre de las casas inglesas más modestas (Dyer, 1994: 136.) y está en el rango de 500-1000 $\mathrm{m}^{2}$ de las irlandesas (O’Sullivan \& Nicholl, 2011: 63). Parece razonable presumir la compartimentación del solar entre un sector trasero, al norte de la casa, de unos $265 \mathrm{~m}^{2}$, y un patio principal delantero de $480 \mathrm{~m}^{2}$. La ocupación se fecha entre algún momento del siglo VI y finales del VII o inicios del VIII (Prata, 2017: 419; 2019).

\subsection{Congosto (Rivas-Vaciamadrid, Madrid)}

El conjunto doméstico CD1 de Congosto ocupa la parte septentrional y más alta de la ladera explorada (Vigil-Escalera \& Strato, 2013: 244-258). La restitución del contorno 
ovalado de la parcela se apoya en varios tramos de trincheras documentados al norte y al oeste, y por la alineación dentro de esos límites de una serie de estructuras cuya huella la conforman amplios rebajes o recortes en el terreno geológico al sur. Su eje largo, con orientación NNO-SSE, mediría unos 58 metros, y el corto alrededor de 42, lo que determina una superficie aproximada de $1870 \mathrm{~m}^{2}$ (Fig. A3). La vivienda ocupa una posición centrada, algo desplazada al sur. El acceso al solar parece situarse al sur, entre el punto donde termina el amplio rebaje de la instalación meridional y el último tramo reconocido de la trinchera perimetral, tal vez la huella dejada por un cercado de madera.

Otra trinchera, esta vez rectilínea, con orientación ENE-OSO, compartimenta un área al norte del solar de unos 15 metros de fondo $\left(330 \mathrm{~m}^{2}\right.$ en total). Su mitad oriental presenta dos grandes cocinas de suelo rehundido de planta subrectangular (cada una de ellas con horno adosado), mientras que la occidental carece de restos de estructuras.

Por lo que respecta al bloque meridional, los rebajes conforman con bastante probabilidad la huella de una construcción amplia, de 22 metros de largo por 5,70 de ancho (unos $116 \mathrm{~m}^{2}$ ), en la que sería posible reconocer dos sectores diferenciados. El tercio oriental presenta huellas de diversas fosas poco profundas en su interior, y queda separado del resto por una alineación de tres silos que previsiblemente se ubicaban, como los dos documentados unos metros al oeste, anejos al exterior de la construcción. La interpretación de este edificio -o de una parte de él- como zona de estabulación de ganado es congruente con la evidencia arqueológica y con lo que se conoce sobre las trazas de instalaciones con esa función en otras regiones europeas (Zimmermann, 1999a, 1999b). Las siete únicas estructuras de almacenamiento subterráneo (silos) asignables al grupo doméstico se concentran en ese sector meridional de la parcela.

La cerámica doméstica y varias determinaciones radiocarbónicas sugieren una ocupación comprendida entre el último cuarto del siglo v y el primer tercio del siglo vi d. C. (Vigil-Escalera \& Strato, 2013: 255-257, Tabla 2.22). Los escasos silos ${ }^{7}$ avalarían la brevedad de la ocupación, un par de generaciones a lo sumo. Debe aducirse, en contraste, el número de estructuras de fuego: dos hogares en la vivienda principal y dos cocinas separadas y un posible horno exento en el reducto norte. A la luz de los datos, es posible que las estructuras asignadas al conjunto doméstico CD2, ladera abajo (al sur), pertenezcan a una ocupación inmediatamente sucesiva: una reconstrucción desplazada del grupo originalmente asentado en el lugar.

7. Serían pocos de acuerdo con los parámetros de otros asentamientos de esta comarca, aunque no tanto frente a cualquiera de los asentamientos altomedievales excavados, por ejemplo, en la Llanada alavesa. 


\subsection{Navalvillar (Colmenar Viejo, Madrid)}

El despoblado se localiza en la rampa granítica que conecta las campiñas del Tajo y sus tributarios con el Sistema Central, a unos $975 \mathrm{~m} \mathrm{s.} \mathrm{n.} \mathrm{m.} \mathrm{La} \mathrm{parcela} \mathrm{en} \mathrm{que} \mathrm{se} \mathrm{insertan}$ las edificaciones excavadas se ha restituido a partir de fotografías aéreas de los años 19611967, en las que también se reconocen otros edificios y cercados similares en el entorno. Las distintas granjas que conformaron el asentamiento se distribuyen al oeste de un regato estacional. Entre sus respectivas parcelas discurren caminos bordeados por tapias, con trazados irregulares adaptados a la configuración de los recintos (Fig. A4).

El conjunto de estructuras excavado (Abad, 2006) se enmarca en un amplio recinto oblongo, probablemente construido en piedra, cuyo tramo norte no se ha podido establecer con fiabilidad (Fig. A5). Los edificios se disponen en su tercio occidental. Un tramo de la cerca se conserva en el lado sur, donde previsiblemente había un acceso. El recinto ofrece un eje largo de 88-90 metros en dirección ENE-OSO y entre 57 y 70 metros en el corto, para una extensión de entre 3.900 y $5.000 \mathrm{~m}^{2}$. La parte edificada comprende una serie de estancias rectangulares alineadas formando una L invertida. Delimitan por el norte y el este un patio de $930 \mathrm{~m}^{2}$ al que se abren las habitaciones. Este alberga a su vez otras construcciones auxiliares, entre las que destaca un posible granero. La parcela doméstica en la que se incluyen los edificios y el patio ocupa $1.370 \mathrm{~m}^{2}$. La amplitud del recinto externo tal vez pueda relacionarse con el peso de la ganadería en el régimen económico de la explotación.

Los materiales exhumados pertenecen sobre todo a la última ocupación durante el siglo VIII d. C., aunque existe ruido de fondo que retrotraería la frecuentación del área hasta el siglo $\mathrm{V}$ d. C. Al margen de la vajilla cerámica característica destacan un fragmento de cinturón con placa liriforme y un dirhem acuñado en Damasco en el 715-716 d. C.

\subsection{Gózquez (San Martín de la Vega, Madrid)}

Las parcelas analizadas en este sitio se localizan en su barrio oriental (al este del cementerio), que fue el sector excavado de forma intensiva. Ocupan una ladera suave orientada a norte, que desciende hasta un regato tributario de la margen derecha del Jarama. El diseño del parcelario ofrece unas características singulares, ya que se trata del único yacimiento en el que la lotización se mantiene sin cambios sustanciales a lo largo de toda la secuencia de ocupación, entre la primera mitad del siglo vi y mediados del viII d. C. Diversas publicaciones han abordado cuestiones específicas, tales como sus cabañas, el repertorio cerámico, las fases de ocupación o una lectura de sus 
estrategias productivas (Vigil-Escalera \& Strato, 2013: 155-177; Vigil-Escalera et al., 2014).

\subsubsection{Gózquez CD1}

Este conjunto doméstico ocupa una posición preeminente en la topografía del barrio oriental. Consta de dos bloques, separados por un camino vallado (Fig. A6). El occidental es la parcela edificada o solar. En su centro se construyeron a mediados del siglo VII un edificio residencial de planta compleja y un posible lagar, en sustitución de otras construcciones previas. El oriental es una parcela de cultivo, un probable huerto, que permaneció libre de estructuras durante la ocupación plurisecular del sitio.

La parcela edificada mide entre 28 y 32 metros de ancho por 78 de largo $\left(2370 \mathrm{~m}^{2}\right)$ y muestra una planta rectangular bastante regular. La delimitación de su perímetro se basa en distintas evidencias. Fija su límite oriental una larga trinchera rectilínea. El meridional muestra un tramo de zanja perpendicular al anterior, con idénticos rasgos. Su límite occidental queda configurado en su mitad sur por una alineación de fosas colindantes con una parcela de probable uso agrario, vacía de estructuras, al oeste. La parte norte de ese mismo límite discurre a lo largo de la línea de cierre marcada por las traseras de diversos edificios pertenecientes al grupo doméstico vecino. El lado norte del solar es el único que presenta alguna incertidumbre. Se ha trazado en correspondencia con la alineación de sendas cabañas rehundidas, aunque no es descartable que se ubicara algo más al norte, coincidiendo con un ligero quiebro de la línea de la trinchera oriental. Tal vez se abriese allí una portilla de acceso al camino.

La parcela de huerto tiene forma trapezoidal, con sus lados largos paralelos. Mide 43 metros de ancho por 80 de largo, y tiene una extensión de $3500 \mathrm{~m}^{2}$. Linda a norte y oeste con el trazado de sendos viales, y al este con una parcela en la que se documentan diversas estructuras. La restitución hipotética de su límite meridional se ha fijado como prolongación de la parcela edificada aneja.

\subsubsection{Gózquez CD2}

Se localiza aneja al norte de la parcela agraria de CD1. Tiene planta trapezoidal, de 31/37 metros de ancho por 63 de largo (unos $1870 \mathrm{~m}^{2}$ ). La vivienda principal, compuesta por dos módulos rectangulares, ocupa una posición centrada ligeramente desplazada a sur y queda alineada con el límite oriental del solar (Fig. A7). 
Su límite meridional lo marcan un tramo de zócalo y el desarrollo de la trinchera de la parcela agraria aneja. El oriental se reconoce en su mitad sur por la alineación de las traseras de varios edificios y un tramo de zócalo de tapia. La mitad norte de este lado se ha trazado prolongando el desarrollo virtual de otras partes comprobadas del perímetro. El lado norte del solar lo señalaría la trasera de un edificio que ocupa la esquina $\mathrm{NO}$ del mismo. El desarrollo de este edificio señala también el borde occidental del solar, cuyo trazado se sigue con facilidad a partir de las numerosas estructuras alineadas a lo largo de la parte interior del recinto.

\subsection{Cuarto de las Hoyas (Pelayos, Salamanca)}

El asentamiento ha sido objeto de excavaciones muy limitadas, aunque se dispone de un levantamiento topográfico en el que se aprecian numerosas construcciones en piedra diseminadas por unas tres hectáreas y un lote de material cerámico en su mayoría procedente de prospecciones de superficie (Storch, 1998). El hecho de encontrarse en una dehesa, lejos de lugares habitados, ha favorecido la preservación del sitio, en la actualidad bajo las aguas de un embalse.

El despoblado se dispone a orillas de un regato, en una solana de pendiente suave, a $810 \mathrm{~m} \mathrm{s.} \mathrm{n.} \mathrm{m.} \mathrm{De} \mathrm{acuerdo} \mathrm{con} \mathrm{la} \mathrm{planta} \mathrm{publicada} \mathrm{y} \mathrm{los} \mathrm{restos} \mathrm{visibles} \mathrm{en} \mathrm{fotografía}$ satélite cuando desciende la lámina de agua, podrían distinguirse unos siete u ocho conjuntos domésticos con sus correspondientes parcelas delimitadas por tapias de piedra, además de otras edificaciones indeterminadas (Fig. A8). Las parcelas, de entre $400 \mathrm{y}$ $700 \mathrm{~m}^{2}$, ofrecen contornos poligonales irregulares, con caminos serpenteantes entre las casas.

La cerámica, la epigrafía sobre pizarra y un broche de cinturón de placa liriforme permitirían sostener una ocupación del lugar entre la segunda mitad del siglo v y el vIII d. C. Esta amplitud cronológica es coherente con los resultados del análisis de los edificios preservados. En la foto fija final que muestra la planta del sitio se reconocen conjuntos domésticos levantados a partir de otros anteriores, que se adosan o modifican la configuración de construcciones previas, de lo que se deduce la sucesión de actividades a lo largo de una secuencia prolongada.

Resulta extraña la ubicación de la posible zona de vivienda del conjunto doméstico meridional (CD8) al sur del patio. Parece ir contra la orientación casi normativa de los vanos de las viviendas, mirando al mediodía. No se descarta que ese espacio casi triangular pueda haber sido el patio trasero -y no el delantero- de la casa. El conjunto doméstico 
CD7 (al este) ofrece una de las parcelas más pequeñas del sitio $\left(404 \mathrm{~m}^{2}\right)$, pero en su lado oeste tiene anejo un edificio con los rasgos propios de un establo con aprisco (similar por ejemplo al del sector P02 de El Pelícano, véase abajo).

El desarrollo orgánico de las construcciones se advierte bien en el núcleo central que forman los conjuntos 1 al 5 . El elemento más antiguo sería CD1. A este se le adosan el 5 (por el sudeste) y el 2 (por el oeste). No sería raro que una parcela doméstica original bastante amplia haya sido subdividida entre dos herederos. En todo caso, a la número 2 se le adosan en un momento posterior las numeradas 3 y 4 . La ubicación de este racimo de parcelas en el centro del asentamiento, además de su larga secuencia constructiva, podría ser indicio de una cierta primacía en el seno del hábitat.

\subsection{E1 Pelícano (Arroyomolinos, Madrid)}

$\mathrm{El}$ asentamiento se localiza a orillas de un tributario del río Guadarrama, unos $40 \mathrm{~km}$ al norte de la ciudad de Toledo, y fue excavado en extensión entre 2002 y 2010 (Vigil-Escalera \& Strato, 2013: 177-201). La ocupación campesina se constituyó sobre el dominio de un establecimiento de época romana, desestructurado a inicios del siglo $\mathrm{V}$ d. C. A pesar de las transformaciones operadas en el patrón residencial de la aldea durante más de tres siglos de actividad, el cementerio comunitario permaneció fijo en torno a los mausoleos de la antigua hacienda.

El análisis de la documentación inédita llevado a cabo para este trabajo ha permitido individualizar 21 conjuntos domésticos, cuya actividad cabría situar a lo largo de tres fases. A la primera (450-600 d. C.) pertenecen cinco casas en el sector P09, tres en P07 y una en P01. A la segunda, fechada en el siglo VII, se asocian cinco UD del sector P02, dos en P01, una en P04 y otra en P06. A la tercera fase (siglo VIII) se adscriben dos casas en el sector P10 y una en P05 (Fig. A9). La variedad en lo tocante a la forma, dimensiones y componentes de los solares domésticos es muy amplia. Ciertas transformaciones pueden apreciarse adoptando una perspectiva diacrónica. La diversidad es el rasgo que predomina al inicio de la secuencia. Durante la segunda fase se identifican los solares de mayores dimensiones. En la tercera encontramos UD distanciadas y de modestas dimensiones. Los límites parcelarios son restituibles con relativa fiabilidad solo en media docena de casos. 


\subsubsection{P02_CD2}

El sector presenta una alta densidad de ocupaciones, aunque todas las UD reconocidas se asignan a la segunda fase. El conjunto más completo es el denominado CD2, encajado entre otros tres al oeste, este y sur (Fig. A10). Lo conforman dos bloques separados por una zona de tránsito en el sentido de la pendiente (NNO-SSE), con una superficie conjunta que ronda los $2060 \mathrm{~m}^{2}$.

El bloque oriental comprende instalaciones residenciales y auxiliares. En la parte alta de la ladera se encuentra la vivienda principal, compuesta por dos módulos de planta rectangular unidos por su lado corto, con vanos de acceso independientes al sur. Al norte se abre un patio o corral trasero. Ante la vivienda se adosaron varias estancias o porches, con cubiertas de teja. Hasta media docena de huellas de hogares se identificaron en estas piezas. El patio delantero muestra en su ala oeste una serie de estancias con zócalo de piedra (al menos cinco), con funciones diversas. La crujía del lado opuesto puede restituirse a partir de la alineación de diversas estructuras. Un posible pozo ocupa el centro del patio, cuyo cierre meridional es menos seguro de establecer.

El bloque oeste presenta en su extremo septentrional un edificio amplio (15 por 11 metros) dividido en dos o tres naves. No presenta hogares ni parece haber tenido cubierta de teja, pudiendo tratarse de un aprisco. Ladera abajo se identifica al menos otro edificio o recinto en muy precario estado de conservación.

\subsubsection{P01_CD3-4}

La ocupación de este sector es bastante menos densa, aunque también se fecha en la segunda fase. No ha sido posible reconocer los límites de ningún conjunto doméstico completo, pero diversas estructuras lineales (zanjas) revelan un parcelario de traza ortogonal, con la misma orientación que los vestigios de edificios (Fig. A11).

No se han reconocido con claridad parcelas agrarias intercaladas en el área residencial. Varias áreas libres de estructuras compatibles con esa función no han librado huellas de límites. No es descartable que los huertos se hayan emplazado a orillas del arroyo, a menos de cien metros al sur de las casas. Un análisis reciente de la documentación altomedieval señala la estrecha asociación entre huertos y espacios irrigados (Davies, 2019: 336). 


\subsection{Peñaflor (Jaén)}

El asentamiento del Cerro del Castillo ocupa un lugar elevado sobre su entorno, a 610 m s. n. m., protegido por vertientes pronunciadas. El emplazamiento limita la disponibilidad de espacio residencial y conlleva el distanciamiento del hábitat respecto de su terrazgo. Esta es una diferencia cualitativa con respecto a los restantes casos estudiados. Las excavaciones exhumaron una porción significativa del hábitat de época emiral (siglo IX a inicios del x d. C.) que permite apreciar su organización interna. El conjunto lo habrían formado entre 20 y 30 casas, de las que se documentaron unas diez (Salvatierra \& Castillo, 1995: 16; Salvatierra, Castillo \& Aguirre, 2000). Para este análisis hemos seleccionado las seis más completas (Fig. A12). Todas disponen de un patio abierto al que se abren las diferentes estancias en dos o tres de sus lados, quedando despejado el flanco sur, suroeste o sudeste, dependiendo de la orientación del conjunto.

CD1, la más occidental, tiene planta ligeramente trapezoidal, con eje NO-SE. Contrasta con el resto de los conjuntos, cuyos ejes predominantes discurren N-S o NE-SO. Sus crujías se disponen en los lados NE y SO del patio, que cierra por el sudeste adosándose al perímetro de $\mathrm{CD} 2$. Su acceso posiblemente se situó contra el cierre de la casa vecina. CD2 es la casa más amplia y compleja de las excavadas, con seis estancias. Su formato es más o menos rectangular. El lado corto norte denota transformaciones cuyos detalles son difíciles de esclarecer. CD3 conforma una especie de anejo de la anterior por su lado SE. Presenta dos estancias en el lado oeste de un patio poligonal. La planta de CD4 parece haberse amoldado al espacio libre entre CD3 y CD5, de las que queda separada por estrechos pasadizos. Alberga cinco estancias, y su acceso pudo estar al norte o al sur del patio. El conjunto CD5 constituye en realidad la fusión de dos módulos sencillos de planta en L, cada uno con su patio y tres estancias. CD6 es la casa de formato más simple, de planta cuadrada y crujías en tres de sus lados, dejando libre el sur. Su acceso se realizaría desde el oeste, por un pasillo hasta el patio.

Como en Cuarto de las Hoyas, se aprecia claramente el desarrollo orgánico del caserío, con sucesivas adaptaciones a lo largo de la ocupación. Resolver la trama del viario público queda a expensas de ubicar con precisión dónde estaban los accesos a cada unidad, aspecto para el que falta evidencia suficiente. Las dimensiones de los solares y patios y el número de habitaciones de cada casa revelan una considerable heterogeneidad: de los 340 $\mathrm{m}^{2}$ del solar de $\mathrm{CD} 2$ a los $160 \mathrm{~m} 2$ de CD6; de las dos estancias de CD3 a las seis de CD2; de los $40 \mathrm{~m}^{2}$ del patio de CD6 a los $170 \mathrm{~m}^{2}$ de CD2. 


\subsection{Valle de Jolopos (Peza, Granada)}

Las investigaciones desarrolladas en esta comarca comprendieron tanto asentamientos en alto (Majada de las Vacas y qarya de Jolopos, respectivamente emiral y califal) como en el fondo de valle (Bertrand, Sánchez Viciana \& Garrido, 1999; Bertrand \& Sánchez Viciana, 2001). La morfología de las casas del valle es similar a muchas de las vistas anteriormente, incluido Peñaflor, aunque muestran solares de mayor tamaño. Se les atribuye una cronología desde el siglo IX al XI d. C.

Los dos casos analizados responden a un mismo esquema: tres o cuatro módulos rectangulares dispuestos a lo largo de uno de los lados del patio, con sus vanos orientados al sur (Fig. A13). El solar mayor mide unos 40 metros de largo por 27 de ancho $\left(905 \mathrm{~m}^{2}\right)$, con un patio de alrededor de $680 \mathrm{~m}^{2}$. El solar de menores dimensiones tiene 30 por 16 metros y una superficie aproximada de $390 \mathrm{~m}^{2}$, de los que 240 corresponderían al patio ${ }^{8}$.

\subsection{Alcariais dos Guerreiros da Cima (Almodôvar, Portugal)}

La intervención arqueológica registró al menos cinco conjuntos domésticos sobre unas lomas de relieve suave (Melro, Gonçalves \& Clélia, 2004). En todos se reconoce un patio delantero descubierto y cerrado. Dos de las casas tienen formato en $\mathrm{L}$, dos en $\mathrm{U}$ y la quinta presenta edificado solamente el lado noroeste. Esta última y la que tiene aneja al SE fueron seleccionadas para este análisis (Fig. A14). La adaptación del ambiente suroeste del CD2 al trazado de la tapia del CD1 daría a entender que la implantación de la casa meridional se produjo estando ya en activo la norte.

La parcela de la casa norte CD1 mide 19 metros de largo por 15 de ancho $\left(250 \mathrm{~m}^{2}\right.$, de los que 150 corresponderían al patio). Muestra al menos dos estancias de función residencial en la crujía del lado NO. El ambiente de planta semicircular del ángulo NE del patio es un rasgo reseñable, aunque no se ha resuelto su interpretación. La parcela del $\mathrm{CD} 2$ tiene un formato rectangular, con al menos tres espacios residenciales o auxiliares dispuestos en L a lo largo del norte y oeste del solar. Mide unos 16 metros de largo por 13 de ancho $\left(186 \mathrm{~m}^{2}\right.$, de los que 90 corresponden al patio).

La ocupación del sitio se ha fechado entre los siglos XI-XIII (Melro, Gonçalves, A. \& Clélia, 2004: 63), posiblemente sobre un establecimiento anterior (siglos IX-X).

8. Estas medidas difieren muy poco de las publicadas (BERTRAND, SÁNCHEZ ViCIANA \& GARRIDO, 1999: 35), 960 y $380 \mathrm{~m}^{2}$, respectivamente. Los perímetros de los patios son aproximados. 


\section{FIGURA 3}
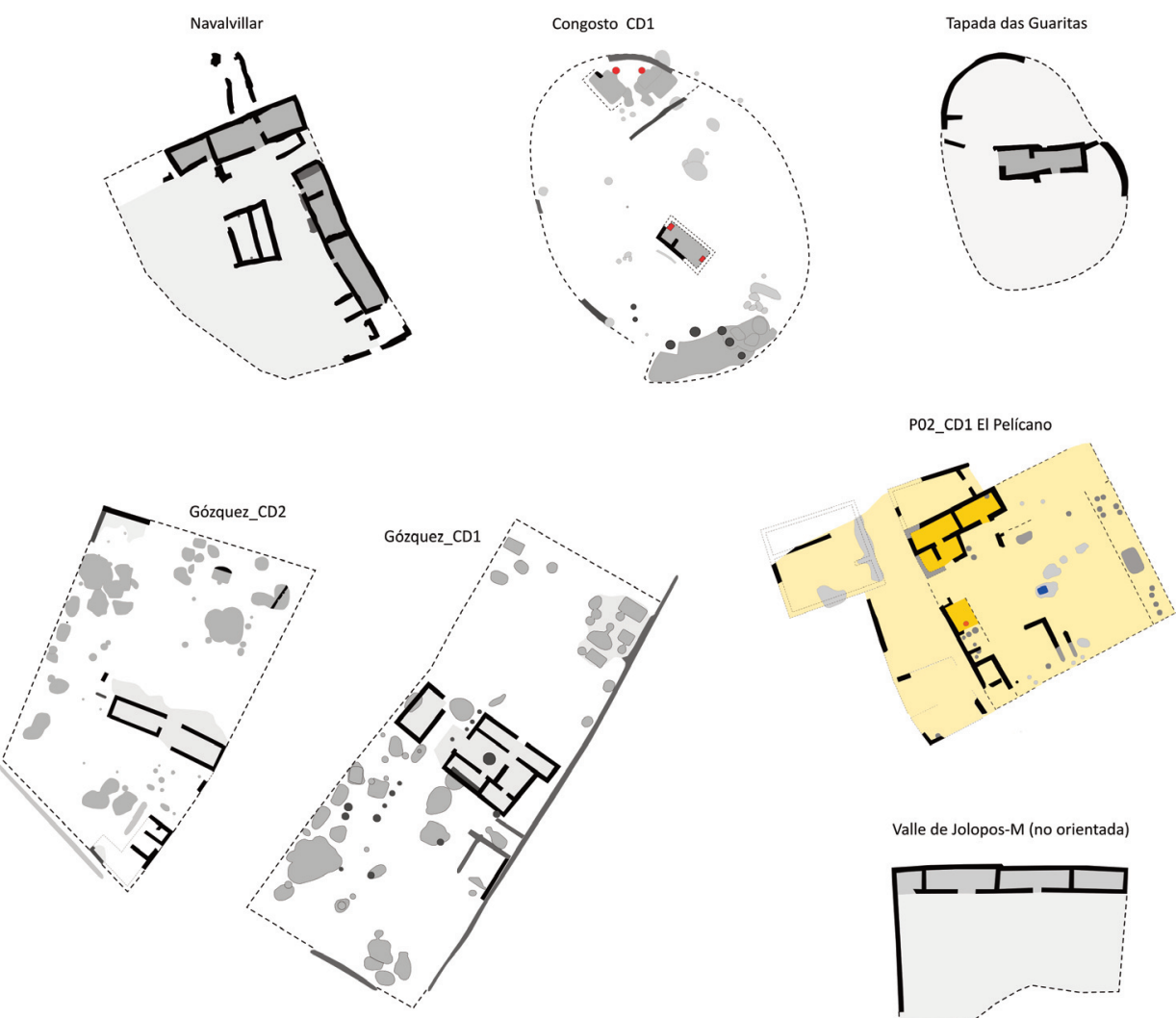

Valle de Jolopos-M (no orientada)
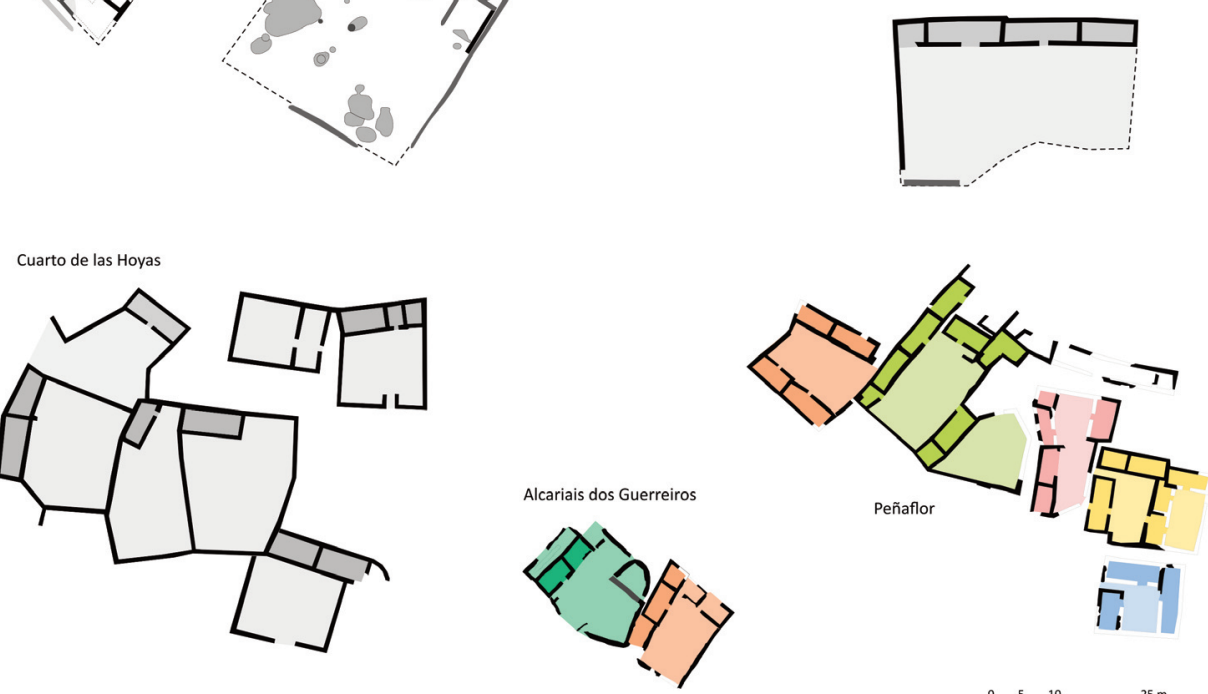

Comparativa a escala de algunas de las parcelas domésticas examinadas en el trabajo. 
TABLA 1

Dimensiones de las parcelas domésticas analizadas

\begin{tabular}{|c|c|c|c|c|}
\hline Yacimiento & UD & Largo (máx./mín.) & Ancho (máx./mín.) & Superficie $\left(\mathrm{m}^{2}\right)$ \\
\hline \multirow[t]{2}{*}{ Gózquez } & CD1 & 78 & $28 / 32$ & 2.370 \\
\hline & CD2 & 63 & $31 / 37$ & 1.870 \\
\hline Congosto & CD1 & 58 & 42 & 1.870 \\
\hline Navalvillar & NV1 & 45 & $34 / 25$ & 1.370 \\
\hline Tapada das Guaritas & TG1 & 39 & 28 & 870 \\
\hline Lancha del Trigo & LT1 & 45 & 17 & 730 \\
\hline \multirow[t]{2}{*}{ El Pelícano } & P07_CD1 & 37 & 29 & 1.060 \\
\hline & P02_CD2 & 43 & 52 & 2.060 \\
\hline \multirow[t]{8}{*}{ Cuarto de las Hoyas } & CD1 & 30 & $16 / 25$ & 690 \\
\hline & CD2 & 35 & $12 / 18$ & 510 \\
\hline & CD3 & 26 & 23 & 620 \\
\hline & CD4 & 25 & $14 / 22$ & 430 \\
\hline & CD5 & 24 & 22 & 525 \\
\hline & CD6 & - & - & 530 (mín.) \\
\hline & CD7 & 22 & 19 & 690 \\
\hline & CD8 & 26 & $17 / 30$ & 500 \\
\hline \multirow[t]{2}{*}{ Alcariais dos Guerreiros } & CD1 & 19 & 15 & 250 \\
\hline & CD2 & 16 & 13 & 186 \\
\hline \multirow[t]{6}{*}{ Peñaflor } & CD1 & 15,5 & 16 & 240 \\
\hline & CD2 & 26 & 18 & 340 \\
\hline & CD3 & 23 & 17 & 177 \\
\hline & $\mathrm{CD} 4$ & 20 & $9 / 13$ & 202 \\
\hline & CD5 & 18,5 & 15 & 258 \\
\hline & CD6 & 13 & 12 & 160 \\
\hline \multirow[t]{2}{*}{ Valle de Jolopos } & Mayor & 40 & 27 & 905 \\
\hline & Menor & 30 & 16,5 & 390 \\
\hline
\end{tabular}

\subsection{Otros sitios}

Varios sitios preseleccionados fueron a la postre excluidos por distintos motivos. Las Sillas (Huesca), era un candidato idóneo para representar al valle del Ebro (Sénac, 2009). La cronología (siglos X-XII) y un repertorio amplio de viviendas jugaban a su favor, pero las restricciones derivadas del emplazamiento en altura y la morfología tan regular y urbana de sus casas determinó el descarte. Cabezo Pardo (Alicante), un sitio especialmente atractivo como bisagra entre el siglo VIII y el IX, se excluyó por carecer de alguna casa com- 


\section{GRÁFICO 1}

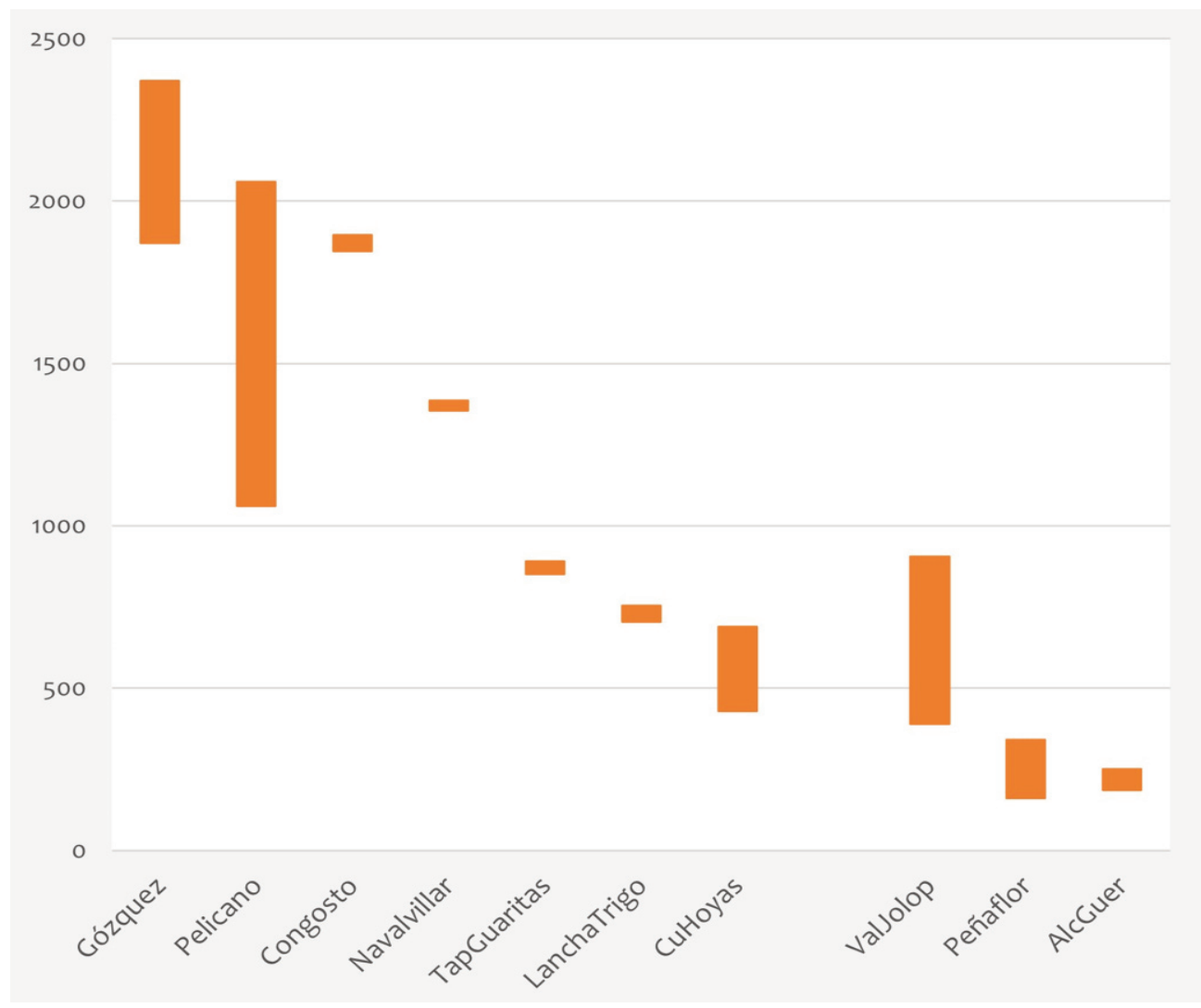

Dimensiones (máxima y mínima, en $\mathrm{m}^{2}$ ) de las parcelas analizadas en distintos yacimientos.

pleta $^{9}$ (López Padilla \& Ximénez de Embún, 2014). Los datos de Alcaria Longa (Boone, 2019) son redundantes con Guerreiros en cronología, formatos y emplazamiento, y ninguna de sus parcelas está íntegra. Los casos de Odeleite (Algarve) y El Quemao (Teruel) quedan fuera por su avanzada cronología (Santos, 2007; Ortega \& Villargordo, 2020), como ocurre con varias alquerías albacetenses (Simón, 2016). Por restricciones de espacio se han omitido descripciones del sector P07 de El Pelícano y de la casa de Lancha del Trigo, en Ávila (Gutiérrez Palacios, Díaz \& Maluquer de Motes, 1958), aunque sus mediciones constan en la Tabla 1 y el Gráfico 1 .

9. Se cita un conjunto doméstico de cronología emiral, con patio descubierto amplio, de unos 250 $\mathrm{m}^{2}$ (López PAdilla \& XiméneZ de EMBún, 2014: 213), cuyas dimensiones entrarían en el rango de Peñaflor. 


\section{DISCUSIÓN}

La documentación muestra la existencia de tres formatos principales de parcelas domésticas: redondeado, rectangular y poligonal. Esas diferencias no corresponden a ámbitos geográficos precisos. Se registran parcelas oblongas, tanto en sitios del valle medio del Tajo (Madrid) como en su tramo inferior (Alto Alentejo). Tampoco se aprecian rasgos idiosincráticos entre los emplazamientos de las vegas fluviales, las campiñas o el piedemonte serrano.

Se constata que algunas parcelas de perímetro curvo corresponden a ocupaciones unifamiliares sin vecinos en el entorno inmediato, que colonizan un espacio hasta entonces libre de impedimentos. No es descartable que el parcelario ortogonal pueda ser producto -al menos en parte- de una regulación inducida por la cohabitación de unidades domésticas en un entorno poblado con intensidad, cuando las ocupaciones se fijan en el espacio y tienden a ser más prolongadas (se inhibe la posibilidad de reconstruir la casa a poca distancia de la anterior). La dificultad de manejar resoluciones cronológicas que discriminen periodos generacionales obstaculiza la lectura de las relaciones existentes entre casas vecinas.

Solo en Gózquez se ha comprobado fehacientemente la presencia de parcelas agrarias cerradas anejas al solar. Un análisis comparado de la posible correspondencia entre el solar edificado y el huerto sería todavía prematuro, por falta de testimonios suficientes.

Los datos tampoco permitirían establecer una relación directa entre el tamaño del solar y la riqueza o prosperidad del grupo doméstico residente, al menos a título preliminar. Como ha señalado Dyer (2013:24) la fortuna de una casa campesina puede ser cambiante, incluso a lo largo de una única generación. A veces son circunstancias estrictamente biológicas las que determinan la posibilidad de mantener o incrementar la fuerza de trabajo de la unidad, que en otras ocasiones marcan su debilitamiento, fuerzan la integración de sus miembros en una casa vecina o abocan a su extinción. El repertorio analizado incluye unidades domésticas con un nivel de recursos a su disposición seguramente por encima de la media, y otras que subsistirían con los medios estrictamente imprescindibles.

El análisis de El Pelícano revela que la estabilidad residencial durante los primeros siglos de la Alta Edad Media está sujeta a altibajos drásticos. No parece que ninguna UD permanezca en el mismo solar durante más de un siglo o siglo y medio (3-5 generaciones). El contraste con la secuencia plurisecular atestiguada en el edificio E8 del asenta- 
miento alavés de Zornoztegi resulta revelador ${ }^{10}$ (Quirós, 2019: 534-535). La inmutabilidad del parcelario de Gózquez supone de momento una singularidad, aunque la ocupación apenas rebasa los dos siglos (525-750 d. C.).

La interrupción de las secuencias de ocupación en muchos lugares a lo largo del siglo viII d. C. entorpece de momento el reconocimiento del desarrollo de los asentamientos en un determinado territorio entre el periodo visigodo y el emiral/califal. En algunos casos son reconocibles eventos de destrucción y colapsos estructurales. En otros los abandonos parecen ordenados. Se ha aludido a veces a un fenómeno de emigración masiva del campo a arrabales urbanos o a nuevos núcleos de población, en alto o en llano, que se estarían gestando entre la segunda mitad del siglo viII y la primera del IX d. C. Este proceso generador de nuevos centros está atestiguado a escala continental durante el largo siglo viII, aunque puede ofrecer particularidades en el caso ibérico. El hiato en las secuencias dificulta evaluar cuáles serían las tendencias en las sociedades campesinas peninsulares, si determinadas familias estaban despegando de sus vecinas concentrando riqueza y cuotas de influencia social o si otras veían empeorar sus circunstancias y posibilidades de remontar.

La diferencia existente en el tamaño de los solares de unos asentamientos a otros resulta llamativa. Ordenadas cronológicamente, las parcelas de los sitios de época califaltaifa son las de menor extensión, seguidas de las emirales. Es necesario hacer una salvedad a este respecto. Los datos de Peñaflor no pueden compararse con el resto sin tener en cuenta las constricciones derivadas de su emplazamiento en cuanto a disponibilidad de terreno. Los solares de las granjas del Valle de Jolopos son considerablemente mayores que los de sus vecinas encaramadas de la Majada de las Vacas o de la alquería de Jolopos, pero también que los de Alcariais dos Guerreiros, un sitio abierto y sin limitaciones reconocibles de espacio. No hallamos razones de peso para explicar la significativa reducción de tamaño de la casa rural de época califal y taifa ${ }^{11}$. Se ha sugerido que la vivienda rural tiende con el paso de los siglos a adoptar un aspecto más urbano, pero esto describe el cambio sin esclarecer las causas. La forma de explotar el terrazgo o el grado de especialización productiva pueden ser factores relevantes, pero la evidencia arqueológica con la que sostener tales argumentos es todavía escasa o inconcluyente. La diversidad de regímenes de explotación, agraria y pecuaria, su grado de intensidad o la escala

10. A diferencia de otras estructuras residenciales documentadas en el sitio, ésta se mantuvo en uso entre las fases 4 a y $4 \mathrm{~b}$ (siglos VIII-XI).

11. En regiones de Europa septentrional se advierte un cambio significativo en torno a mediados del siglo viII d. C., con un aumento del tamaño de la parcela doméstica y del número y especialización de las construcciones auxiliares (MIKKELSEN, 2000: 51). 
a la que se practicaron los cultivos irrigados deberían orientar la discusión de estos aspectos en el futuro, tal y como se está haciendo en otros ámbitos europeos (McKerracher, 2019). Sería conveniente trascender los límites del dilema básico en torno al tipo de plantas, frutos o ganado explotado de forma mayoritaria en cada sitio. Finalmente, permanece de momento huérfana de explicación la variación registrada en las dimensiones de los solares entre sitios coetáneos con un entorno ambiental análogo, caso por ejemplo de Navalvillar y Cuarto de las Hoyas.

\section{CONCLUSIONES}

El presente estudio plantea sin duda más interrogantes que respuestas. Es una situación incómoda, aunque también un incentivo para perseverar en esta dirección. Cuanto más avanza la investigación, mayor diversidad aflora (Pesez, 1990: 192). El primer propósito de este trabajo era doble: suscitar la cuestión de las parcelas domésticas y esbozar un protocolo de análisis con sus resultados preliminares. El objetivo en el horizonte es desbordar las restricciones a las que queda sometido el estudio del espacio doméstico rural de la Edad Media cuando se autolimita a los ambientes residenciales.

$\mathrm{El}$ inventario ha comprendido 26 conjuntos domésticos de diez yacimientos. En un primer lote se han revisado las parcelas de 16 casas en siete asentamientos con cronologías que van de finales del siglo $\mathrm{v}$ al siglo vIII. En el segundo grupo se examinaron diez ejemplos de parcelas domésticas de tres sitios, dos de cronología emiral y otro califal-taifa.

Ha podido apreciarse cómo las dimensiones del solar doméstico se reducen con el paso de los siglos. Por regla general, la casa rural tendió a hacerse más compleja, aumentando la especialización de sus componentes. La relación de este proceso con el incremento de la participación de los campesinos en actividades comerciales (la venta de una parte cada vez mayor de sus productos en mercados) constituye un factor relevante en el tránsito de la Alta a la Plena y Baja Edad Media. Esto no implica que la granja altomedieval pueda seguir caracterizándose en los términos primitivistas que le ha atribuido una parte de la historiografía tradicional. El campesinado de esa época estaba muy lejos de vivir en el aislamiento, e intercambios de todo tipo eran habituales (Vigil-Escalera, 2019). Frente a postulados evolutivos a veces demasiado estrictos (véase Boone, 2019), se ha defendido aquí que la vivienda rural, por modesta que fuese, siempre debió contar con un espacio doméstico propio. Así debió ser desde el momento en que es posible hablar de economía campesina, con lo que ello implica de capacidad de gestión de la producción por la unidad doméstica. 
Este trabajo ha procurado integrar registros de ámbitos que por desgracia apenas mantienen comunicación: del periodo visigodo al andalusí y de contextos postrromanos a fechas plenomedievales. La investigación sobre el mundo rural medieval requiere rebasar divisorias historiográficas que obstaculizan el desarrollo del conocimiento. En este sentido, los datos dejan en evidencia ciertas lecturas del registro arqueológico formuladas en clave étnico-cultural que derivan de apriorismos sin fundamento. Se ha sostenido, por ejemplo, que la cocina separada de la vivienda testimoniaría la separación de mujeres y hombres en una sociedad islamizada, o que la multiplicación de estancias tendría relación con la estructura familiar de los clanes bereberes migrantes. Ambos fenómenos son rastreables, sin embargo, desde mucho antes de la conquista ${ }^{12}$.

De la muestra analizada se desprende que el universo rural alberga infinidad de matices. Afloran desigualdades que pueden llegar a ser sustanciales entre unidades domésticas, que eran y siguen siendo difíciles de identificar y evaluar. Estos aspectos merecen una mayor atención y un trabajo tenaz orientado a reunir y cuantificar datos, someterlos a análisis comparativos y desentrañar su significado.

La adecuada documentación de evidencias relacionadas con delimitaciones parcelarias es un reto para la práctica arqueológica desde el momento en que se comprende su eventual trascendencia. El análisis de los asentamientos rurales a partir de la evolución de las unidades domésticas que los integran constituye una avenida insuficientemente explorada, que además despeja múltiples nuevos itinerarios. Ofrece posibilidades heurísticas para alcanzar un mejor conocimiento crítico del desarrollo histórico del medio rural y de las sociedades medievales. La potencialidad de la investigación sobre la parcela doméstica esbozada en el presente trabajo, a pesar de sus limitaciones y de los errores que habrán de corregirse en adelante, es susceptible de aprovechamiento por quienes investigan en este campo desde el registro escrito y el material, estimula el desarrollo de nuevas aproximaciones y promueve la renovación de los protocolos de documentación arqueológica aplicados a estos ámbitos, tanto en lo que atañe a la planificación y ejecución de las intervenciones de campo como a las reflexiones y síntesis sobre la domesticidad campesina.

\section{AGRADECIMIENTOS}

Este trabajo ha sido realizado en el marco del proyecto «Agencia campesina y complejidad sociopolítica en el noroeste de la Península Ibérica en época medieval» (Ministerio

12. Se ha reconocido el fracaso a la hora de enlazar la teoría clásica del parentesco con el registro material (ORTEGA, 2018: 270). 
de Economía, Industria y Competitividad, AEI/FEDER UE HUM2016-76094-C4-2-R), del Grupo de Investigación en Patrimonio y Paisajes Culturales (Gobierno Vasco, IT93616) y del Grupo de Estudios Rurales (Unidad Asociada UPV/EHU-CSIC).

Mi agradecimiento a los revisores de Historia Agraria. Este trabajo se gestó a partir de distintos eventos organizados por Ignasi Grau, Sonia Gutiérrez Lloret, Elena Díez Jorge, Julio Navarro, Jesús Bermejo, Catarina Tente y Sara Prata para reflexionar sobre el espacio doméstico. Carlos Tejerizo, Sara Prata, Margarita Fernández Mier y Juan Antonio Quirós me hicieron sugerencias para mejorar el borrador. Los errores y defectos que subsisten son de mi responsabilidad.

\section{REFERENCIAS}

ABAD, Concepción (2006). El poblado de Navalvillar (ColmenarViejo). Zona arqueológica, 8 (2), 388-399.

Alcock, Nat W. (2003). The Medieval Peasant at Home: England, 1250-1550. En Cordelia Beattie, Anna Maslakovic \& Sarah Rees Jones (Eds.), The Medieval Household in Christian Europe, c. 850-c. 1550: Managing Power, Wealth, and the Body (pp. 449-468). Turnhout: Brepols.

Allison, Penelope M. (Ed.) (1999). The Archaeology of Household Activities. London/New York: Routledge.

AstiLl, Grenville (1988). Rural Settlement:The Toft and the Croft. En Grenville AstiLL \& Annie Grant (Eds.), The Countryside of Medieval England (pp. 36-51). Oxford: Blackwell.

Ballesteros, Paula, Kirchner, Helena, Fernández Mier, Margarita, Ortega, Julián, Quirós, Juan Antonio, Retamero, F., Sitjes, Eulalia, TorRó, Josep \& VigIl-EsCALERA, Alfonso (2010). Por una arqueología agraria de las sociedades medievales hispánicas: Propuesta de un protocolo de investigación. En Helena KIRCHNER (Ed.), Por una arqueología agraria: Perspectivas de investigación en las sociedades medievales hispánicas (pp. 185-202). Oxford: Archaeopress.

BARILE, Kerri S. \& BRANDON, Jamie C. (Eds.) (2004). Household Chores and Household Choices: Theorizing the Domestic Sphere in Historical Archaeology. Tuscaloosa: University of Alabama.

BAzZANA, André (1990). Maisons rurales du Shark al-Andalus: Essai de typologie. En Jesús BERMúdez LóPEZ \& André BAZZANA (Coords.), La casa hispano-musulmana: Aportaciones de la arqueología (pp. 247-267). Granada: Patronato de La Alhambra y Generalife. 
Bazzana, André (1992). Maisons d'Al-Andalus: Habitat médiéval et structures de peuplement dans l'Espagne orientale. Madrid: Casa de Velázquez.

BAZZANA, André (2002). La maison rurale dans la péninsule ibérique: Un atelier d'ethnoarchéologie. En Jan KLAPSTE (Ed.), The Rural House from the Migration Period to the Oldest Still Standing Buildings (pp. 216-231). Praha: Archeologický ústav Akademie $\mathrm{v} d$ eské republiky.

BAZZANA, André \& Hubert, Étienne (Coords.) (2000). Castrum 6: Maisons et espaces domestiques dans le monde méditerranéen au Moyen Âge. Roma: École Française de Rome.

Bermejo, Jesús (2014). Household Archaeology y el análisis de las sociedades antiguas en la península Ibérica: Definiciones, aplicaciones y posibilidades. Materialidades: Perspectivas actuales en cultura material, (2), 47-92.

Bertrand, Maryelle \& SÁnchez Viciana, José (2001). Jolopos (La Peza, Granada): Un hisn de la fitna. En Isabel C. F. FernaNDEs (Coord.), Mil Anos de Fortificaçôes na Península Ibérica e no Magreb (500-1500): Actas do Simposio Internacional sobre Castelos 2000, Palmela (pp. 145-159). Lisboa: Colibri.

BERTRAnd, Maryelle, SÁnchez Viciana, José \& Garrido, José Antonio (1999). Poblamiento y explotación del territorio en la región de Guadix-Baza durante el Medievo. Anuario arqueológico de Andalucía 1999 II: Actividades sistemáticas (pp. 30-40). Sevilla: Junta de Andalucía.

Blanton, Richard E. (1994). Houses and Households: A Comparative Study. New York: Springer Science.

Boone, James L. (2019). La organización de los asentamientos rurales en relación con la formación del Califato en al-Andalus: El caso del Alentejo portugués. En María Mercedes Delgado \& Luis Gethsemaní Pérez Aguilar (Eds.), Economía y trabajo: Las bases materiales de la vida en al-Andalus (pp. 17-42). Sevilla: Alfar.

BROOKES, Stuart \& REYNOLDS, Andrew (2019). Territoriality and Social Stratification: The Relationship between Neighbourhood and Polity in Anglo-Saxon England. En Julio Escalona, Orri VésteInsson \& Stuart BRookes (Eds.), Polity and Neighborhood in Early Medieval Europe (pp. 267-304). Turnhout: Brepols.

Davies, Wendy (2019). Gardens and Gardening in Early Medieval Spain and Portugal. Early Medieval Europe, 27 (3), 327-348.

Díaz ANDreu, Margarita \& Montón, Sandra (2012). Feminist and Gender Issues in Southwestern Europe: Spanish, Portuguese and French Prehistoric Archaeologies. En Diane L. Bolger (Ed.), A Companion to Gender Prehistory (pp. 438-445). Oxford: Wiley-Blackwell.

Díez Jorge, María Elena \& NAvarro, Julio (Eds.) (2015). La casa medieval en la península Ibérica. Madrid: Sílex. 
DYER, Christopher C. (1994). Everyday Life in Medieval England. London: Hambledon. Dyer, Christopher C. (2013). Living in Peasant Houses in Late Medieval England. Vernacular Architecture, 44 (1), 19-27.

EiroA, Jorge Alejandro (2012). Past and Present of the Archaeology of the Alquerías. Imago Temporis Medium Aevum, (6), 49-72.

FERNÁNDEZ FERNÁNDEZ, Jesús (2017). Arqueología de una aldea medieval y su espacio agrario:Villanueva de Santo Adriano (Asturias, noroeste de la península ibérica). Historia Agraria, (72), 69-106.

FernándeZ FernándeZ, Jesús \& Fernández Mier, Margarita (Eds.) (2019). The $A r-$ chaeology of Medieval Villages Currently Inhabited in Europe. Oxford: Archaeopress.

Frankel, David \& WebB, Jennifer M. (2006). Neighbours: Negotiating Space in a Prehistoric Village. Antiquity, 80 (308), 287-302.

GARCÍA CAMINO, Iñaki (1998). La vivienda medieval: perspectivas de investigación desde la arqueología. En José Ignacio DE LA IGLESIA (Coord.), La vida cotidiana en la Edad Media:VIII Semana de Estudios Medievales (Nájera, 1997) (pp.77-110). Logroño: Instituto de Estudios Riojanos.

GARCÍA FERNÁNDEZ, Jesús (1980 [1976]). Sociedad y organización tradicional del espacio en Asturias. Gijón: Silverio Cañada.

Gerritsen, Fokke A. (2008). Domestic Times: Houses and Temporalities in Late Prehistoric Europe. En Andrew Jones (Ed.), Prehistoric Europe:Theory and Practice (pp. 143-161). Chichester: Wiley-Blackwell.

González Marcén, Paloma, Montón, Sandra \& Picazo, Marina (2008). Towards an Archaeology of Maintenance Activities. En Sandra MonTón \& M. SÁnchez Romero (Eds.), Engendering Social Dynamics: The Archaeology of Maintenance Activities (pp. 3-8). Oxford: Archaeopress.

GutiérRez Lloret, Sonia (2012). Gramática de la casa: Perspectivas de análisis arqueológico de los espacios domésticos medievales en la península Ibérica (siglos VIIXIII). Arqueología de la arquitectura, (9), 139-164.

GutiÉRrez Lloret, Sonia (2013). Coming Back to Gramar of the House: Social Meaning of Medieval Households. En Sonia GutiérRez Lloret \& Ignasi Grau (Eds.), De la estructura doméstica al espacio social: Lecturas arqueológicas del uso social del espacio (pp. 245-264). Alicante: Universidad de Alicante.

GUTIÉRREZ LLORET, Sonia (2015). Casa y casas: Reflexiones arqueológicas sobre la lectura social del espacio doméstico medieval. En María Elena DíEz Jorge \& Julio NAVARRO (Eds.), La casa medieval en la península Ibérica (pp. 17-48). Madrid: Sílex.

GutiÉrRez Lloret, Sonia \& GrAu, I. (Eds.) (2013). De la estructura doméstica al espacio social: Lecturas arqueológicas del uso social del espacio. Alicante: Universidad de Alicante. 
Gutiérrez Palacios, Arsenio, Díaz, Manuel \& Maluquer de Motes, Juan (1958). Excavaciones en la Lancha del Trigo, Diego Álvaro (Ávila). Zephyrus, (9), 59-78.

Hammel, Eugene A. \& LasletT, Peter (1974). Comparing Household Structure over Time and between Cultures. Comparative Studies in Society and History, 16 (1), 73-109.

Hegyi, Alexandru, SARris, Apostolos, CurTa, Florin, Floca, Cristian, Fortiu, Sorin et al. (2020). Deserted Medieval Village Reconstruction Using Applied Geosciences. Remote Sensing, 12 (12).

HerLihy, David (1985). Medieval Households. Harvard: Harvard University Press.

Hinsch MikKelsen, Jari, Langohr, Roger, VANwesenbeECK, Veerle, Bourgeois, Ignace \& De ClercQ, Wim (2019). The Byre's Tale: Farming Nutrient-Poor Cover Sands at the Edge of the Roman Empire (NW-Belgium). En Judit DEÁK, Carole AMPE \& Jari Hinsch Mikkelsen (Eds.), Soils as Records of Past and Present: From Soil Surveys to Archaeological Sites: Research Strategies for Interpreting Soil Characteristics (pp. 6588). Bruges: Raakvlak.

HiRTH, Kenneth G. (1992). The Household as an Analytical Unit: Problems in Method and Theory. En Robert S. SANTLEY \& Kenneth G. HIRTH (Eds.), Prehispanic Domestic Units in Western Mesoamerica: Studies of the Household, Compound and Residence (pp. 21-36). Boca Ratón: CRC Press.

JonEs, Richard (2010). The Village and the Butterfly: Nucleation out of Chaos and Complexity. Landscapes, (1), 25-46.

KIRCHNER, Helena (Ed.) (2010). Por una arqueología agraria: Perspectivas de investigación en las sociedades medievales hispánicas. Oxford: Archeopress.

KIRCHNER, Helena (2020). La arqueología del campesinado en época alto-medieval: Reflexiones y propuestas. Imago Temporis. Medium Aevum, (14), 462-497.

KowAleski, Maryanne \& Goldberg, P. Jeremy P. (Eds.) (2008). Medieval Domesticity: Home, Housing and Household in Medieval England. New York: CUP.

Laurence, Ray \& Wallace-Hadrill, Andrew (Eds.) (1997). Domestic Space in the Roman World: Pompeii and Beyond. Oxford: Oxbow.

López Padilla, Juan Antonio \& Ximénez de Embún, Teresa (2014). Excavaciones arqueológicas en Cabezo Pardo (San Isidro/Granja de Rocamora, Alicante): Últimas actuaciones. En Manuel H. Olcina \& Jorge A. Soler (Eds.), Arqueología en Alicante en la primera década del siglo XXI: II fornadas de arqueología y patrimonio alicantino (pp. 209-214). Alicante: Museo Arqueológico de Alicante.

Martín Civantos, José María \& Bonet, María Teresa (2015). MEMOLA Project: Mediterranean Mountainous Landscapes: An Historical Approach to Cultural Heritage Based on Traditional Agrosystems. PCA Post-Classical Archaeologies, (5), 347-356. McKerracher, Mark (2019). Anglo-Saxon Crops and Weeds: A Case Study in Quantitative Archaeobotany. Oxford: Archaeopress. 
Melro, Samuel, Gonçalves, Alexandre \& ClÉlia, Sandra (2004). Intervenção arqueológica nos Alcariais dos Guerreiros de Cima (Almodôvar): Resultados preliminares. Era-arqueología, (6), 63-81.

MikKELSEN, Dorthe Kaldal (2000). Single Farm orVillage? Settlement Structure during the Late Iron Age and Viking Period. En Jan KLÁpste (Ed.), Ruralia III: Conference Ruralia III, Maynooth, 3rd-9th September 1999 (pp. 46-59). Turnhout: Brepols.

Moore, Tom (2007). The Early to Later Iron Age Transition in the Severn-Cotswolds: Enclosing the Household?. En Colin Haselgrove \& Rachel Pope (Eds.), The Earlier Iron Age in Britain and the Near Continent (pp. 259-278). Oxford: Oxbow.

NAVARRo, Julio (1990). La casa andalusí en Siyasa: Ensayo de una clasificación tipológica. En Jesús BERMúdez LóPEZ \& André BAzZANA (Coords.), La casa hispano-musulmana: Aportaciones de la arqueología (pp. 177-198). Granada: Patronato de la Alhambra y Generalife.

NetTing, Robert MCC., WiLK, Robert R. \& ARnould, Eric J. (Eds.) (1984). Households: Comparative and Historical Studies of the Domestic Group. Berkeley: University of California.

Ortega, Julián M. (2018). La conquista islámica de la Península Ibérica: Una perspectiva arqueológica. Madrid: La Ergástula.

ORTEGA, Julián M. \& VILLARGORDO, Carolina (2020). ¿Campesinos ricos en al-Ándalus?: Comunidades rurales, estratificación interna y formas de consumo en la alquería de El Quemao (Sarrión, Teruel). En Actualidad de la investigación arqueológica en España I (2018-2019): Conferencias impartidas en el Museo Arqueológico Nacional (pp. 177196). Madrid: Museo Arqueológico Nacional.

O'Sullivan, Aidan \& Nicholl, Tríona (2011). Early Medieval Settlement Enclosures in Ireland: Dwellings, Daily Life and Social Identity. Proceedings of the Royal Irish Academy, (111C), 59-90.

PARKer, Bradley J. \& Foster, Catherine P. (Eds.) (2012). New Perspectives on Household Archaeology. Winona Lake: Eisenbrauns.

Pesez, Jean-Marie (1990). Archéologie de la maison paysanne. En Actes des congrès de la Société des historiens médiévistes de l'enseignement supérieur public, 21e congrès, Caen, 1990:Villages et villageois au Moyen Âge (pp. 181-192). Paris: Publications de la Sorbonne.

Pesez, Jean-Marie (Ed.) (1998). Archéologie du village et de la maison rurale au Moyen Age. Lyon: Presses universitaires de Lyon.

PRATA, Sara (2017). Objectos arqueológicos alto-medievais em contexto doméstico: O caso da Tapada das Guaritas (Castelo de Vide, Portugal). Mediaeval Sophia, (19), 413429.

PRATA, Sara (2019). Post-Roman Land-Use Transformations: Analysing the Early Medieval Countryside in Castelo deVide (Portugal). En Niall BRADY \& Claudia THEUNE 
(Eds.), Settlement Change across Medieval Europe: Old Paradigms and NewVistas (pp. 65-72). Leiden: Sidestone.

Quirós, Juan Antonio (2011). La arquitectura doméstica de los yacimientos rurales en torno al año 711 . Zona arqueológica, 15 (2), 63-82.

QUiRós, Juan Antonio (2018). La compleja interpretación de los registros arqueológicos domésticos de las sociedades locales altomedievales. En Catarina Tente (Ed.), Do império ao reino:Viseu e o território entre os séculos IV a XII (pp. 24-43). Viseu: Câmara municipal de Viseu.

QUIRós, Juan Antonio (2019). Una propuesta interpretativa de Zornoztegi, desde la prehistoria reciente hasta nuestros días. En Juan Antonio Quirós (Ed.), Arqueología de una comunidad campesina medieval: Zornoztegi (Álava) (pp. 515-558). Bilbao: Universidad del País Vasco.

Quirós, Juan Antonio, Nicosia, Cristiano, Polo-Díaz, Ana \& RuIZ DEL Árbol, María (2013). Agrarian Archaeology in Northern Iberia: Geoarchaeology and Early Medieval Land Use. Quaternary international, (346).

REYNOLDS, Andrew (2003). Boundaries and Settlements in Later Sixth to Eleventh-Century England. En David GRIFFITHS, Andrew REYNolds \& Sarah SEMPLE (Eds.), Boundaries in Early Medieval Britain (pp. 98-136). Exeter: Oxbow.

RoBerts, Brian K. (1996). Landscapes of Settlements: Prehistory to the Present. London/New York: Routledge.

SAlVATIERRA, Vicente \& CASTILlo, Juan Carlos (1995). Peñaflor, un établissement rural d'époque émirale dans la Campiña de Jaén. Archéologie islamique, (5), 11-24.

Salvatierra, Vicente, Castillo, Juan Carlos \& Aguirre, Javier (Eds.) (2000). Los asentamientos emirales de Peñaflor y Miguelico: El poblamiento hispano-musulmán de Andalucía oriental: La Campiña de faén (1987-1992). Sevilla: Junta de Andalucía.

SANTOS, Filipe J.C. (2007). O povoado rural (qarya) dos Alcariais de Odeleite. Vipasca arqueología e história, (2), 571-589.

SÉNAC, Philippe (2009). Un 'village' d'al-Andalus aux alentours de l'an Mil: Las Sillas (Marcén, province de Huesca). Toulouse: Framespa.

Simón, José Luis (2016). El poblamiento islámico en Albacete: Alquerías y castillos. En Actas de la I Reunión Científica de Arqueología de Albacete (pp. 659-682). Albacete: Diputación de Albacete.

STORCH, Jacobo (1998). Avance de las primeras actividades arqueológicas en los yacimientos hispano-visigodos de la Dehesa del Cañal (Pelayos, Salamanca). Arqueología, paleontología y etnografía, (4), 141-160.

SWAN, Leo (1994). Ecclesiastical Settlement in Ireland in the Early Medieval Period. En L'environnement des églises et la topographie religieuse des campagnes médiévales: Actes du III congrès international d"archéologie médiévale (Aix-en-Provence, 28-30 septembre 1989) (pp. 50-56). Caen: Société d'archéologie médiévale. 
Tejerizo, Carlos (2012). Early Medieval Household Archaeology in Northwest Iberia ( $6^{\text {th }}$ $11^{\text {th }}$ Centuries). Arqueología de la arquitectura, (9), 181-194.

VEEN, Marijke van der (2005). Gardens and Fields:The Intensity and Scale of Food Production. World Archaeology, 37 (2), 157-163.

VIGIL-ESCALERA, Alfonso (2007). Granjas y aldeas altomedievales al norte de Toledo (450800 d. C.). Archivo español de arqueología, (80), 239-284.

VigIL-EsCALERA, Alfonso (2019). Meeting Places, Markets, and Churches in the Countryside between Madrid and Toledo, Central Spain (c. AD 500-900). En Julio EsCALONA, Orri VésteInsson \& Stuart BRookes (Eds.), Polity and Neighborhood in Early Medieval Europe (pp. 173-202). Turnhout: Brepols.

Vigil-EsCALERA, Alfonso \& STRATO (2013). El registro arqueológico del campesinado del interior peninsular en época altomedieval. En Juan Antonio QuiRós (Ed.), El poblamiento rural de época visigoda en Hispania: Arqueología del campesinado en el interior peninsular (pp. 65-259). Bilbao: Universidad del País Vasco.

Vigil-Escalera, Alfonso, Moreno, Marta, Peña, Leonor, Morales, Arturo, LloRENTE, Laura, SABATo, Diego \& UCChesu, Mariano (2014). Productive Strategies and Consumption Patterns in the Early Medieval Village of Gózquez (Madrid, Spain). Quaternary international, (346), 7-19.

WilK, Richard \& RATHJE, William L. (1982). Household Archaeology. American Behavioral Scientist, 25 (6), 617-639.

YANAGISAKo, Sylvia J. (1979). Family and Household:The Analysis of Domestic Groups. Annual Review of Anthropology, (8), 161-206.

ZimmermanN, W. Haio (1999a). Why was Cattle-Stalling Introduced in Prehistory?:The Significance of Byre and Stable and of Outwintering. En Charlotte FABECH \& Jytte Ringtved (Eds.), Settlement and Landscapes: Proceedings of a Conference in Arhus, Denmark, May 4-7 1998 (pp. 301-318). Aarhus: Jutland Archaeological Society.

ZimmermanN, W. Haio (1999b). Favourable Conditions for Cattle Farming, one Reason for the Anglo-Saxon Migration over the North Sea?: About the Byre's Evolution in the Area South and East of the North Sea and England. En Herbert SARFati, W. H.VERWers \& P. J.Woltering (Eds.), In Discussion with the Past: Archaeological Studies Presented to W.A. van Es (pp. 129-144). Zwolle: Stichting promotie archeologie. 